\title{
Social media use and well-being: What we know and what we need to know Patti M. Valkenburg
}

\begin{abstract}
Research into the impact of social media use (SMU) on wellbeing (e.g., happiness) and ill-being (e.g., depression) has exploded over the past few years. From 2019 to August 2021, 27 reviews have been published: nine meta-analyses, nine systematic reviews, and nine narrative reviews, which together included hundreds of empirical studies. The aim of this umbrella review is to synthesize the results of these metaanalyses and reviews. Even though the meta-analyses are supposed to rely on the same evidence base, they yielded disagreeing associations with well- and ill-being, especially for time spent on SM, active SMU, and passive SMU. This umbrella review explains why their results disagree, summarizes the gaps in the literature, and ends with recommendations for future research.
\end{abstract}

\begin{abstract}
Addresses
Amsterdam School of Communication Research, University of Amsterdam, the Netherlands

Corresponding author: Valkenburg, Patti M (p.m.valkenburg@uva.nl)
\end{abstract}

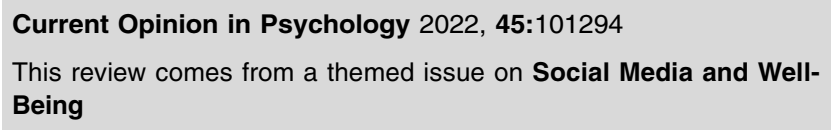
open access article under the CC BY license (http://creativecommons. org/licenses/by/4.0/).

\section{Keywords}

Review, Meta-analysis, Facebook, Instagram, Social media, Mental health, Well-being, Depression, Idiographic approach, Social comparison, Problematic social media use.

\section{Introduction}

It is almost a truism: In the past decade, social media have become a massive and meaningful part of our daily existence. Individuals, adults and adolescents alike, use

This research was funded by an NWO Spinoza grant. Many thanks to Wieneke Rollman for assisting with the literature search, and to Loes Keijsers for her comments on the first draft. on average five social media platforms in a complementary way [1], to interact privately with family members and friends, and/or to interact publicly with broader audiences of friends, acquaintances, and colleagues [2]. In parallel with this surging social media use (SMU), research into its potential impact on well-being (e.g., life satisfaction) and ill-being (e.g., depression) has also accumulated dramatically [3]. As recent reviews demonstrate [4-6], the past years have witnessed at least 300 studies on the impact of SMU on well- and ill-being.

Together with the exponential increase in empirical studies, reviews of the impact of SMU on well- and illbeing have also surged in the past few years. Because this rapidly expanding research output makes it ever more difficult for researchers to keep track of it, an upto-date umbrella review of this literature is necessary and important. An umbrella review, also called a metareview, is a synthesis of existing reviews [7]. Three earlier umbrella reviews have focused on the associations of SMU with well- and ill-being [3,8,9]. One of these focused on adolescents, thereby excluding reviews on adults [9], and neither of the two others included the 22 reviews on the effects of SMU on well-/ill-being published in 2020 and 2021.

In this article, I first outline the search method of this umbrella review as well as the operational definitions of SMU, well-being, and ill-being. To assess "what we know," I use the meta-analyses to discuss the associations of seven different types of SMU with well- and illbeing. The systematic and narrative reviews are used to complement the meta-analytical results, as well as to summarize the identified gaps in the literature and the suggestions for future research. To assess "what we need to know," the article ends with some general conclusions and three additional recommendations for future research.

\section{Method and operational definitions}

Two coders used the same search strategy and terms as applied in the umbrella review of Valkenburg et al. [9], except for the search terms related to adolescents (as the current umbrella review excluded reviews focusing on adolescents). SMU was operationally defined as the active (e.g., posting), passive (e.g., browsing), private, 
and public uses of platforms such as Facebook, WeChat, and WhatsApp. As for the outcomes of SMU, the focus lied on three well-being components (happiness; life satisfaction; positive affect) and three ill-being components (depressive symptoms/depression; anxiety symptoms/anxiety; negative affect). Due to space restrictions, other components of well-being (e.g., eudaimonic well-being) and ill-being (e.g., stress), as well as risk and resilience factors of well- and ill-being, such as self-esteem, cyberbullying, and body image concerns, were not considered.

\section{Results: what we know ...}

The search yielded 27 reviews: nine meta-analyses $[4,6,10-16]$, nine systematic reviews [5,17-24], and nine narrative reviews [25-33] published from January 2019 to August 2021. Except for five meta-analyses, which included studies on both adolescents and adults, none of the remaining 22 reviews were included in the earlier umbrella review of Valkenburg et al. [9].

\section{Seven social media activities}

As Table 1 shows, some meta-analyses investigated (a) general time spent with SM, or (b) time spent with active and (c) passive SMU. Some (also) focused on specific behaviors and mechanisms afforded by SM, including (d) the size of one's SM network, (e) the intensity of SMU, (f) problematic SMU (i.e., an enduring preoccupation with SM, reflected in a persistent neglect of one's own health and important life areas), and (g) SM-induced social comparison (the tendency to observe others to assess how we are looking, thinking, or behaving in comparison with these others) [34].

\section{Conceptualizations of well-being and ill-being}

Two out of the nine meta-analyses [6,12] reversed different ill-being components (e.g., depression) and combined them with well-being components (e.g., life satisfaction) to create an "aggregated well-/ill-being" outcome. Furthermore, five meta-analyses $[6,10,11,14,15]$ lumped together components like life satisfaction and self-esteem to create an "aggregated well-being" outcome. Likewise, they combined components like depression and loneliness to create an "aggregated ill-being" outcome. However, because mental health theories agree that a low well-being (e.g., low life satisfaction) does not necessary imply a high illbeing (e.g., suffering from depression) and vice versa $[8,35,36]$, this umbrella review investigated whether the three aggregated outcomes, that is, (a) aggregated well-/ ill-being, (b) aggregated well-being and (c) aggregated ill-being, led to different associations with SMU.

\section{General SMU}

The three types of aggregated well- and/or ill-being outcomes yielded inconsistent associations with general SMU (also called time spent using SM, general SNS use, or the frequency of SM checking). As for aggregated well-/ill-being, one meta-analysis yielded no association [6], and another a small positive association with general SMU [12]. As for aggregated well-being, one metaanalysis yielded a small negative [6], and another a small positive association with general SMU [15]. Remarkably though, his latter meta-analysis also reported a small positive association with aggregated illbeing [15]. Finally, general SMU was consistently associated with higher levels of depression/depressive symptoms $[4,6,12,16]$ and anxiety [6,12], but, again surprisingly, also with higher happiness levels [12].

\section{Active versus passive social media use}

Three meta-analyses compared time spent on active and passive SMU, again with highly inconsistent results. Active SMU was not [12] or weakly positively associated [6] with aggregated well-/ill-being. Furthermore, it was not [15] or weakly positively associated [6] with aggregated well-being, but not with aggregated ill-being [15]. Passive SMU, in contrast, was not [6] or negatively [12] associated with aggregated well-/ill-being, but not with aggregated well-being [6,15] and not with aggregated ill-being [15]. Yet, both active and passive SMU were associated with higher levels of depression/depressive symptoms [6] and anxiety [6].

In all, the meta-analyses yielded scant support for both the "active SMU hypothesis" and "passive SMU hypothesis," which respectively argue that active SMU elicits likes and support, which results in higher wellbeing/lower ill-being. And that passive SMU induces social comparisons and envy, which leads to lower wellbeing/higher ill-being [37]. An elaborate explanation of this lack of support can be found in a review by Valkenburg et al. [24].

\section{Social comparison}

Even though the direct meta-analytic associations of active and passive SMU with well- and ill-being were inconsistent, two meta-analyses have addressed one part of the passive SMU hypothesis, which states that SMinduced social comparison results in lower well-being/ higher ill-being [33]. Indeed, SM-induced social comparison was associated with lower aggregated well-being and life satisfaction [14] and higher depression [16]. It must be noted, though, that $78 \%$ of SM users report never feeling worse after comparing themselves to other users [38], that only a minority of SM users feel envious while using SM [39], that they more often feel enjoyment [40], and that they sometimes also get inspired from SM-induced social comparisons [41].

\section{Network size}

The results of the two meta-analyses focusing on network size were rather consistent: The size of one's SM network size was associated with higher aggregated well- 
being [11,15], happiness [11], and life satisfaction [11]. It was not [15] or weakly associated [11] with lower aggregated ill-being, and not with depression [11]. Network size was not related to anxiety [11], but negatively to higher social anxiety [11]. However, this latter association has mostly been investigated within the social compensation framework [42], in which social anxiety is conceptualized as a predictor rather than an outcome of SMU. Socially anxious people spend more time on SM [42], but particularly more time on passive SMU [22]. Obviously, expanding one's network does not occur via passive but via interactive SMU, which could explain why socially anxious users tend to have smaller SM networks than their less socially anxious counterparts.

\section{SM intensity and problematic SMU}

Intensity of SMU refers to a mixture of users' emotional attachment to SM and the extent to which SMU is integrated into their lives [4]. It is mostly measured with (adaptions of) the Facebook Intensity Scale (FIS) [43]. Even though the FIS was not designed as a measure of problematic SMU, it is highly correlated with problematic SMU (e.g., $\beta=.57$ ) [44], and in some studies, intensity of SMU is even included as an indicator of problematic SMU [19]. It is no surprise, therefore, that, most meta-analytic effect sizes for intensity of SMU and problematic SMU are not significantly different [4]. Intensity of SMU was consistently associated with lower aggregated well-being [6], higher depression/depressive symptoms [4,6] and higher anxiety [6].

Comparatively, problematic SMU was associated with lower aggregated well-being [6,10], lower happiness [10], and life satisfaction [10]. And it was associated with higher aggregated ill-being [10], depression/ depressive symptoms $[4,6,10,13]$, and anxiety $[6,10]$. A likely explanation for the consistent associations of problematic SMU with well- and ill-being outcomes may lie in "construct overlap" [4]. After all, it should be no surprise that well- and ill-being outcomes correlate with problematic SMU scales consisting of items like "How often during the last year ..." "did you use SM to escape negative feelings" [45] and "have you become restless or troubled if you were prohibited from using social media?" [46].

\section{Identified gaps and directions for future research}

Seventeen out of the 27 reviews agreed that the evidence on which their conclusions were based is primarily cross-sectional and called for longitudinal and/or experimental studies to determine the causal direction of the effects of SMU [3,5,12,28,29,47], or for research designed to investigate why and/or for whom SMU is associated with well- or ill-being [4,5,17,20,31,32]. Other reviews observed an over-reliance on measures of time spent on SM $[4,6,22,28,29]$ and active and passive
SMU [22,24] at the expense of more fine-grained measures, such as the purpose of SMU or the type of communication partners [12,29]. Finally, some reviews criticized the over-reliance on self-reports $[3,5,25,28-$ 30] and called for more objective measures of SMU, such as log-based data obtained though screen-time apps [28,29].

\section{Discussion: what we need to know ...}

The nine meta-analyses in this umbrella review disagreed in their conclusions about the associations of different types of SMU with well-being. This particularly applied to the time-based predictors and not or less to the other predictors. However, despite these inconsistencies, all meta-analyses yielded pooled associations that were mostly small (for the time-based predictors), occasionally moderate (for problematic SMU), but never large. The conclusions of the metaanalyses were largely supported by the narrative and systematic reviews, which observed comparable gaps in the literature and provided comparable suggestions for future research. I end this article with three additional recommendations for future research.

\section{Recommendation 1: don't collapse across well- and ill-being outcomes}

Meta-analyses of the effects of SMU can provide indispensable summaries of the evidence in this vastly expanding literature [3]. But they can also suffer from the same shortcomings as any other type of study. An important shortcoming involves their arbitrary choices to collapse across distinct well-being and ill-being components. In fact, the inconsistencies in effect sizes applied particularly to the six meta-analyses that created well-being, ill-being, and well-/ill-being composites. As Table 1 shows, these meta-analyses collapsed across a great variety of well- and ill-being components in addition to a range of risk and resilience factors of well- and ill-being, such as envy, stress, self-esteem, self-harm, and suicidal ideation.

This lumping together of different well- and ill-being components and their risk-resilience factors hampers the validity of the meta-analytic effect sizes for two reasons. First, ill-being is not simply the flip side of wellbeing [36], as demonstrated, for example, by the positive meta-analytic associations of time spent on SM with both the well-being component "happiness" and the illbeing component "depression" [12]. Second, components within well- or ill-being composites also led to different associations with SMU, as confirmed by the sheer opposite meta-analytic associations of SM network size with anxiety versus social anxiety [11]. Therefore, a first crucial step for future research is to avoid lumping together well- and ill-being components that deserve to be investigated in their own right [30]. 
Table 1

Associations of different types of social media use (SMU) with indicators of well-being and ill-being.

Study \# Articles $\quad \begin{gathered}\text { Operational definitions of } \\ \text { outcomes }\end{gathered} \quad$ Main results

\begin{tabular}{|c|c|c|c|c|}
\hline $\begin{array}{l}\text { Cunningham } \\
\text { et al. (2021) }\end{array}$ & 62 & Depressive symptoms & $\begin{array}{l}r=.11^{*} \\
r=.09 n s \\
r=.29^{*}\end{array}$ & $\begin{array}{l}\text { Time spent on SNS with depressive symptoms } \\
\text { Intensity of SNS use with depressive symptoms } \\
\text { Problematic SNS use with depressive symptoms }\end{array}$ \\
\hline $\begin{array}{l}\text { Hancock } \\
\text { et al. (2019) }\end{array}$ & 256 & $\begin{array}{l}\text { Well-/ill-being = aggregate } \\
\text { of anxiety, depression, } \\
\text { loneliness, \& eudaimonic, } \\
\text { hedonic, and relational } \\
\text { well-being } \\
\text { Hedonic well- } \\
\text { being = aggregate of } \\
\text { happiness, positive affect, } \\
\text { subjective well-being, and } \\
\text { negative affect }\end{array}$ & $\begin{aligned} r & =-.00 \mathrm{~ns} \\
r & =.13^{*} \\
r & =.11^{*} \\
r & =-.03^{*} \\
r & =.11^{*} \\
r & =.10^{*} \\
r & =.13^{*} \\
r & =-.16 n s \\
r & =.06^{*} \\
r & =.08^{*} \\
r & =.06^{*} \\
r & =.06^{*} \\
r & =-.03 \mathrm{~ns} \\
r & =.07^{*} \\
r & =.21^{*} \\
r & =.24 n s \\
r & =-.21^{*} \\
r & =.34^{*} \\
r & =.32^{*} \\
r & =-.26^{*}\end{aligned}$ & $\begin{array}{l}\text { General SMU with well-/lll-being } \\
\text { General SMU with depression } \\
\text { General SMU with anxiety } \\
\text { General SMU with (hedonic) well-being } \\
\text { Intensity of SMU with well-/ill-being } \\
\text { Intensity of SMU with depression } \\
\text { Intensity of SMU with anxiety } \\
\text { Intensity of SMU with (hedonic) well-being } \\
\text { Active SMU with well-/ill-being } \\
\text { Active SMU with depression } \\
\text { Active SMU with anxiety } \\
\text { Active SMU with (hedonic) well-being } \\
\text { Passive SMU with well-/ill-being } \\
\text { Passive SMU with depression } \\
\text { Passive SMU with anxiety } \\
\text { Passive SMU with (hedonic) well-being } \\
\text { Problematic SMU with well-/ill-being } \\
\text { Problematic SMU with depression } \\
\text { Problematic SMU with anxiety } \\
\text { Problematic SMU with hedonic well-being }\end{array}$ \\
\hline Huang (2020) & 123 & $\begin{array}{l}\text { Well-being = aggregate of } \\
\text { life satisfaction, self- } \\
\text { esteem, happiness, and } \\
\text { positive affect } \\
\text { III-being (distress) } \\
\text { = aggregate of } \\
\text { depression, anxiety, } \\
\text { loneliness, and negative } \\
\text { affect }\end{array}$ & $\begin{array}{l}r=-.16^{\star} \\
r=-.30^{\star} \\
r=-.18^{\star} \\
r=-.11^{\star} \\
r=.27^{\star} \\
r=.31^{\star} \\
r=.30^{\star}\end{array}$ & $\begin{array}{l}\text { Problematic SMU with well-being } \\
\text { Problematic SMU with happiness } \\
\text { Problematic SMU with positive affect } \\
\text { Problematic SMU with life satisfaction } \\
\text { Problematic SMU with ill-being } \\
\text { Problematic SMU with depression } \\
\text { Problematic SMU with anxiety }\end{array}$ \\
\hline Huang (2021) & 90 & $\begin{array}{l}\text { Well-being = aggregate of } \\
\text { life satisfaction, self- } \\
\text { esteem, happiness } \\
\text { III-being (distress) } \\
\text { = aggregate of } \\
\text { depression, loneliness, } \\
\text { social anxiety, and } \\
\text { suicidal ideation }\end{array}$ & $\begin{aligned} r & =.08^{*} \\
r & =.15^{*} \\
r & =.10^{*} \\
r & =-.06^{*} \\
r & =.01 \mathrm{~ns} \\
r & =.08 \mathrm{~ns} \\
r & =-.19^{*}\end{aligned}$ & $\begin{array}{l}\text { Network size with well-being } \\
\text { Network size with happiness } \\
\text { Network size with life satisfaction } \\
\text { Network size with ill-being } \\
\text { Network size with depression } \\
\text { Network size with anxiety } \\
\text { Network size with social anxiety }\end{array}$ \\
\hline Liu et al. (2019) & 93 & $\begin{array}{l}\text { Well-/ill-being = aggregate } \\
\text { of life satisfaction, } \\
\text { happiness, self-esteem, } \\
\text { anxiety, depression, } \\
\text { loneliness, and stress }\end{array}$ & $\begin{aligned} r & =-.06^{\star} \\
r & =.09 \mathrm{~ns} \\
r & =.14^{\star} \\
r & =.13^{*} \\
r & =.10^{\star} \\
r & =.02 \mathrm{~ns} \\
r & =-.14^{\star}\end{aligned}$ & $\begin{array}{l}\text { General SNS use with well-/ill-being } \\
\text { General SNS use with life satisfaction } \\
\text { General SNS use with happiness } \\
\text { General SNS use with depression } \\
\text { General SNS use with anxiety } \\
\text { Active SNS use with well-/ill-being } \\
\text { Passive SNS use with well-/ill-being }\end{array}$ \\
\hline Vahedi et al. (2021) & 55 & Depressive symptoms & $\begin{array}{l}r=.11^{\star} \\
r=.27^{*}\end{array}$ & $\begin{array}{l}\text { General SNS use with depressive symptoms } \\
\text { Problematic use with depressive symptoms }\end{array}$ \\
\hline Yang et al. (2019) & 13 & $\begin{array}{l}\text { Well-being = aggregate of } \\
\text { life satisfaction, self- } \\
\text { esteem, and } \\
\text { psychological well-being }\end{array}$ & $\begin{array}{l}r=-.20^{*} \\
r=-.21^{*}\end{array}$ & $\begin{array}{l}\text { Facebook social comparison with well-being } \\
\text { Facebook social comparison with life satisfaction }\end{array}$ \\
\hline Yin et al. (2019) & 63 & $\begin{array}{l}\text { Well-being = aggregate of } \\
\text { life satisfaction, well- } \\
\text { being, self-esteem, and } \\
\text { positive affect } \\
\text { III-being = aggregate of } \\
\text { depression, loneliness, } \\
\text { anxiety, envy, and } \\
\text { negative affect }\end{array}$ & $\begin{aligned} r & =.05^{*} \\
r & =.06^{*} \\
r & =.13^{*} \\
r & =-.03 \mathrm{~ns} \\
r & =.04 \mathrm{~ns} \\
r & =.04 \mathrm{~ns} \\
r & =-.10 \mathrm{~ns} \\
r & =.07 \mathrm{~ns}\end{aligned}$ & $\begin{array}{l}\text { General SNS use with well-being } \\
\text { General SNS use with ill-being } \\
\text { Network size with well-being } \\
\text { Network size with ill-being } \\
\text { Active SNS use with well-being } \\
\text { Active SNS use with ill-being } \\
\text { Passive SNS use with well-being } \\
\text { Passive SNS use with ill-being }\end{array}$ \\
\hline
\end{tabular}




\begin{tabular}{|c|c|c|c|c|}
\hline Study & \# Articles & Operational definitions of & & Main results \\
\hline Yoon et al. (2019) & 45 & Depression & $\begin{array}{l}r=.11^{*} \\
r=.10^{*} \\
r=.23^{*} \\
r=.33^{*}\end{array}$ & $\begin{array}{l}\text { Time spent on SNS with depression } \\
\text { Frequency of checking SNS with depression } \\
\text { Non-directional social comparison with depression } \\
\text { Upward social comparison with depression }\end{array}$ \\
\hline
\end{tabular}

\section{Recommendation 2: we need content-based SM predictors of well- and ill-being}

The inconsistencies in the associations of the timebased SM predictors may be caused by discrepancies in their operationalizations. For example, in some metaanalyses "general SNS use" referred to time spent on SNS [12], in others to a combination of time spent on SNS and the frequency of checking SNS [6,15], and in yet others it was not defined [13].

Unfortunately though, the time-based predictors not only led to heterogeneity across the meta-analyses but also within the meta-analyses (e.g., $I^{2}$ s ranging from $57 \%$ for active SMU [12] to $97 \%$ for time spent on SM [4]), which could not or only partly be explained by moderators like age and gender. However, in case of considerable and (partly) unexplained heterogeneity, metaanalytic effect sizes may not be adequate and reliable [48]. A plausible explanation for the heterogeneity within meta-analyses is that the time-based predictors were operationalized differently in the included empirical studies. This has been confirmed in a recent scoping review, which revealed that of the 40 included survey-based studies, $90 \%$ used a unique, self-created operationalization of active and/or passive SMU, which led to a range of inconsistent associations with well- and ill-being components [24].

Yet even though the synchronization of time-based predictors in meta-analyses and empirical research may be a first step, there are also conceptual concerns. Timebased predictors may simply be too coarse to lead to meaningful associations with well- and ill-being components [30]. Such predictors may be valuable for outcomes like distraction or procrastination, which may be a direct consequence of time spent using SM [49,50]. In addition, they may be valuable when investigating timebased hypotheses, such as the displacement hypothesis, which states that SMU takes away time that could otherwise be spent on activities that are more conducive to well-being than SMU. But since well- and ill-being may be more amenable to the valence of SM interactions (cf. humor vs hate, support vs neglect) than to their duration, a second important step for future research is to pay more attention to content-based SMU predictors [24].

\section{Recommendation 3: we need a causal effect heterogeneity paradigm}

Several reviews have pointed at the need for studies that allow for the investigation of within-person associations of SMU with well-being [24,27]. In recent years, a growing number of such more rigorous studies have appeared [51-56]. But-again-most of these studies found weak average associations with well- and ill-being that were close to zero. What is still too often overlooked in these studies is that such average associations are derived from heterogeneous populations of SM users who differ in how they select and respond to SM [57], a finding that has repeatedly been confirmed in qualitative studies [58]. To truly understand the effects of SMU, researchers need to take the next step, that is, adopting a "causal effect heterogeneity" approach $[59,60]$, which enables them to better understand why and how individuals differ in their responses to SMU.

To my knowledge, two communication research teams have adopted a causal effect heterogeneity paradigm $[50,61]$, which led to the discovery of striking personspecific effects of SMU on well-being. They found, for example, that about $20 \%$ of respondents experienced a negative effect of passive SMU on happiness, $20 \%$ a positive effect, and $60 \%$ no effect at all [51]. A causal effect heterogeneity paradigm may not only help researchers resolve inconsistencies in findings (and replication failures) across studies [60], but it may also help them to arrive at a better understanding of why individuals may or may not be affected by SMU.

A causal effect heterogeneity approach, sometimes called an idiographic or person-specific approach, can be applied in experimental designs [59,62], as well as in non-experimental intensive longitudinal designs (e.g., experience sampling studies) [61,63]. The idiographic approach has recently raised concerns among some communication scholars. One of these concerns is that an idiographic approach in non-experimental settings would hinder inferences from an individual to a targeted 
population. Another concern is that this approach hinders or even ignores the investigation of moderators to explain differences among subgroups in this targeted population $[64,65]$.

While these are valid concerns, they are well addressed in recent idiographic modeling techniques, such as Dynamic Structural Equation Modeling (DSEM), which combine the strengths of "traditional" methods of analysis (i.e., structural equation modelling and multilevel analysis) with $\mathrm{N}=1$ time-series analysis [63]. These modeling techniques require the same sizeable samples to generalize to targeted populations as traditional (nomothetic) approaches do. Also, they can be flexibly used to investigate the role of moderators in the person-specific effects of SMU on certain outcomes, see for example [40,66,67]. In fact, an important strength of these modelling techniques is that they allow for the investigation of two types of moderators, (a) trait-like moderators, such as ethnicity and extraversion, and (b) contextual moderators that are assumed to fluctuate within participants, such as their motivations for using $\mathrm{SM}$, as well as their experience of envy or enjoyment during SMU [40].

Idiographic approaches are thus complementing rather than replacing nomothetic approaches. They enable researchers to report aggregated between-person and within-person associations of SMU with well- and illbeing. And in addition to these aggregated statistics, they can demonstrate for how many participants an experimental treatment works or for how many participants certain hypotheses hold [40]. Moreover, as argued by Bryan et al. [60], a causal effect heterogeneity approach can improve interventions and "make them effective for the diverse gamut of populations and contexts policy must address" (p. 7).

\section{Conclusion}

In sum, in addition to the wealth of valuable suggestions for future research raised in the 27 reviews that have appeared in the past 2.5 years, this umbrella review showed why well-being and ill-being components deserve to be investigated as two separate continuums (see also [8]). In addition, it made a case that we no longer need additional meta-analyses reporting weak aggregate between-person effect sizes of time-based SMU predictors, thereby reiterating the "one-size-fitsall approach" that has long characterized media effects research. Indeed, "we have a bright future before us, and it begins where the average ends." [ [68], p. 191].

\section{Conflict of interest statement}

Nothing declared.

\section{References}

Papers of particular interest, published within the period of review, have been highlighted as:

* of special interest

** of outstanding interest

1. Waterloo SF, Baumgartner SE, Peter J, Valkenburg PM: Norms of online expressions of emotion: comparing Facebook. Twitter Instagram WhatsApp New Media Soc 2018, 20:1813-1831.

2. Bayer JB, Triệu P, Ellison NB: Social media elements, ecologies, and effects. Annu Rev Psychol 2020, 71:471-497.

This is an up-to-date conceptual review of computer-mediated communication and social media. It discusses how SM platforms complicate the study of effects, as well as the challenges and opportunities to measure SMU across time.

3. Appel M, Marker C, Gnambs T: Are social media ruining our lives? A review of meta-analytic evidence. Rev Gen Psychol 2020, 24:60-74.

This is an earlier umbrella review of the effects of social media, based on meta-analyses on well-being, academic performance, and narcisism. It includes a thorough discussion of possible pitfalls of metaanalyses.

4. Cunningham S, Hudson CC, Harkness K: Social media and depression symptoms: a meta-analysis. Res Child Adolesc Psychopathol 2021, 49:241-253.

5. Faelens L, Hoorelbeke K, Cambier R, van Put J, Van de Putte E, De Raedt R, Koster EHW: The relationship between Instagram use and indicators of mental health: a systematic review. Comp Human Behav Rep 2021, 4:100121.

6. Hancock JT, Liu S, X, French M, Luo M, Mieczkowski H: Social media use and psychological well-being: a meta-analysis. In 69th annual international communication association conference, Washington, D.C.; 2019.

7. Aromataris E, Fernandez R, Godfrey CM, Holly C, Khalil H, Tungpunkom P: Summarizing systematic reviews: methodological development, conduct and reporting of an umbrella review approach. JBI Evi Implement 2015, 13:132-140.

8. Meier A, Reinecke L: Computer-mediated communication,

** social media, and mental health: a conceptual and empirical meta-review. Commun Res 2020.

This is another recent umbrella review. It presents the extended twocontinua model of mental health, and gives an excellent review and justification for why we cannot aggregate indicators of well-being and ill-being.

9. Valkenburg PM, Meier A, Beyens I: The effects of social media use on adolescents' mental health: an umbrella review. Curr Opin Psychol 2022, 44:58-68.

10. Huang C: A meta-analysis of the problematic social media use and mental health. Int J Soc Psychiatr 2020. 0020764020978434.

11. Huang C: Correlations of online social network size with wellbeing and distress: a meta-analysis. Cyberpsychology: $J$ Psychosoc Res Cyberspace 2021, 15. Article 3.

12. Liu D, Baumeister RF, Yang C-c, Hu B: Digital communication media use and psychological well-being: a meta-analysis. J Computer-Mediated Commun 2019, 24:259-274.

13. Vahedi Z, Zannella L: The association between self-reported depressive symptoms and the use of social networking sites (sns): a meta-analysis. Curr Psychol 2021, 40:2174-2189.

14. Yang FR, Wei CF, Tang JH: Effect of Facebook social comparison on well-being: a meta-analysis. J Internet Technol 2019, 20:1829-1836.

15. Yin X-Q, De Vries DA, Gentile DA, Wang J-L: Cultural background and measurement of usage moderate the association between social networking sites (SNSs) usage and mental health: a meta-analysis. Soc Sci Comput Rev 2019, 37:631-648. 
16. Yoon S, Kleinman M, Mertz J, Brannick M: Is social network site usage related to depression? A meta-analysis of Facebook-depression relations. J Affect Disord 2019, 248:65-72.

17. Duradoni M, Innocenti F, Guazzini A: Well-being and social media: a systematic review of Bergen addiction scales. Future Internet 2020, 12:24.

18. Gilmour J, Machin T, Brownlow C, Jeffries C: Facebook-based social support and health: a systematic review. Psychol Popular Media 2020, 9:328-346.

19. Hussain Z, Wegmann E, Yang H, Montag C: Social networks use disorder and associations with depression and anxiety symptoms: a systematic review of recent research in China. Front Psychol 2020, 11:211.

20. Karim F, Oyewande AA, Abdalla LF, Chaudhry Ehsanullah R, Khan S: Social media use and its connection to mental health a systematic review. Cureus 2020, 12, e8627.

21. Newman L, Stoner C, Spector A: Social networking sites and the experience of older adult users: a systematic review. Ageing Soc 2021, 41:377-402.

22. O'Day EB, Heimberg RG: Social media use, social anxiety, and Ioneliness: a systematic review. Comp Human Behav Rep 2021, 3:100070.

23. Sharma MK, John N, Sahu M: Influence of social media on mental health: a systematic review. Curr Opin Psychiatr 2020 33:467-475.

24. Valkenburg PM, van Driel II, Beyens I: The associations of active and passive social media use with well-being: a critical scoping review. New Media \& Society 2021, https://doi.org/ 10.31234/osf.io/j6xqz.

25. AIBarashdi HS: Social networking (SNS) addiction among university students: a literature review and research directions. J Educ Soc Behav Sci 2020, 33:11-23.

26. Bettmann JE, Anstadt G, Casselman B, Ganesh K: Young adult depression and anxiety linked to social media use: assessment and treatment. Clin Soc Work J 2021, 49:368-379.

27. Carboni Jiménez A, Vaillancourt M, Zhu P, Seon Q: Social media and mental health: what we know. McGill J Med 2021, 20.

28. Hartanto A, Quek FYX, Tng GYQ, Yong JC: Does social media use increase depressive symptoms? A reverse causation perspective. Front Psychiatr 2021, 12.

This is an insightful narrative review that includes an overview of "social media abstinence" studies, in which participants are asked to stay away from social media for varying durations (e.g., days, weeks). It discusses an important pitfall of most of these experiments: the absence of a "placebo control" condition. Such a control condition avoids that expectancy effects of participants in the abstinencer condition differ from those in the control condition. Everyone who intends to conduct an social media abstinence experiment should read this review, and its suggested references.

29. Griffioen N, Rooij Mv, Lichtwarck-Aschoff A, Granic I: Toward * improved methods in social media research. Technol Mind Behav 2020, 1.

This review identifies itself as a narrative review, but is, in fact, one of the best systematic reviews of 94 empirical studies. It draws attention to many important gaps in the literature and provides several important and well-argued suggestions for future research.

30. Kross E, Verduyn P, Sheppes G, Costello CK, Jonides J, Ybarra O: Social media and well-being: pitfalls, progress, and next steps. Trends Cognit Sci 2021, 25:55-66.

This is an accessible narrative review of the effects of social media use on well-being. It addresses some important pitfalls of the current literature. It acknowledges that it is time to move beyond the active-passive dichotomy, and that a refinement of this dichotomy is necessary.

31. Luo M, Hancock JT: Self-disclosure and social media: motivations, mechanisms and psychological well-being. Curr Opin Psychol 2020, 31:110-115.

32. Mou J, Zhu W, Benyocef M, Kim J: Understanding the relationship between social media use and depression: a systematic review. AMCIS 2020 Proceed 2020:15.
33. Verduyn P, Gugushvili N, Massar K, Täht K, Kross E: Social comparison on social networking sites. Curr Opin Psychol 2020, 36:32-37.

34. Festinger L: A theory of social comparison processes. Hum Relat 1954, 7:117-140.

35. Keyes CLM: Mental illness and/or mental health? Investigating axioms of the complete state model of health. J Consult Clin Psychol 2005, 73:539-548.

36. Ryff CD, Dienberg Love G, Urry HL, Muller D, Rosenkranz MA, Friedman EM, Davidson RJ, Singer B: Psychological well-being and ill-Being: do they have distinct or mirrored biological correlates? Psychother Psychosom 2006, 75:85-95.

37. Verduyn P, Gugushvili N, Kross E: The impact of social network sites on mental health: distinguishing active from passive use. World Psychiatr 2021, 20:133-134.

38. Burke M, Cheng J, de Gant B: Social comparison and Facebook feedback positivity and opportunities for comparison, conference on human factos in computing systems. Honolulu, HI, USA: CHI; 2020.

39. Krasnova $\mathrm{H}$, Widjaja $\mathrm{T}$, Buxmann $\mathrm{P}$, Wenninger $\mathrm{H}$, Benbasat I: Why following friends can hurt you: an exploratory investigation of the effects of envy on social networking sites among college-age users. Inf Syst Res 2015, 26:585-605.

40. Valkenburg PM, Beyens I, Pouwels JL, van Driel II, Keijsers L: Social media browsing and adolescent well-being: challenging the "passive social media use hypothesis,". J Computer-Mediated Commun 2022, 27.

41. Meier A, Gilbert A, Börner S, Possler D: Instagram inspiration: how upward comparison on social network sites can contribute to well-being. J Commun 2020, 70:721-743.

42. Cheng C, Wang H-Y, Sigerson L, Chau C-L: Do the socially rich get richer? A nuanced perspective on social network site use and online social capital accrual. Psychol Bull 2019, 145: 734-764.

This meta-analysis is not included in Table 1 , because it does not fit within a social media effects paradigm. It is an excellent theory-based meta-analysis on the the poor-get-richer/rich-get richer hypotheses, which conceptualize social media use as the outcome and extraversion, social anxiety, and loneliness as the predictors.

43. Ellison NB, Steinfield C, Lampe C: The benefits of Facebook "friends:" Social capital and college students' use of online social network sites. J Computer-Mediated Commun 2007, 12 $1143-1168$.

44. Xie W, Karan K: Predicting Facebook addiction and state anxiety without Facebook by gender, trait anxiety, Facebook intensity, and different Facebook activities. J Behav Addic 2019, 8:79-87.

45. van den Eijnden RJJM, Lemmens JS, Valkenburg PM: The social media disorder scale. Comput Hum Behav 2016, 61:478-487.

46. Andreassen CS, Pallesen S, Griffiths MD: The relationship between addictive use of social media, narcissism, and selfesteem: findings from a large national survey. Addict Behav 2017, 64:287-293.

47. Faelens L, Hoorelbeke K, Soenens B, Van Gaeveren K, De Marez L, De Raedt R, Koster EHW: Social media use and wellbeing: a prospective experience-sampling study. Comput Hum Behav 2021, 114:106510.

48. Melsen WG, Bootsma MCJ, Rovers MM, Bonten MJM: The effects of clinical and statistical heterogeneity on the predictive values of results from meta-analyses. Clin Microbiol Infect 2014, 20:123-129.

49. Siebers T, Beyens I, Pouwels JL, Valkenburg PM: Social media and distraction: an experience sampling study among adolescents. Media Psychol 2021.

50. Aalbers G, vanden Abeele MM, Hendrickson AT, de Marez L, Keijsers L: Caught in the moment: are there person-specific associations between momentary procrastination and passively measured smartphone use? Mobile Media Commun 2021, 2050157921993896. 
51. Beyens I, Pouwels JL, van Driel II, Keijsers L, Valkenburg PM: Social media use and adolescents' well-being: developing a typology of person-specific effect patterns. Commun Res 2021.

52. Coyne SM, Rogers AA, Zurcher JD, Stockdale L, Booth M: Does time spent using social media impact mental health? An eight year longitudinal study. Comput Hum Behav 2020, 104 106160.

53. Hall JA, Xing C, Ross EM, Johnson RM: Experimentally manipulating social media abstinence: results of a four-week diary study. Media Psychol 2021:259-275.

54. Jensen M, George MJ, Russell MR, Odgers CL: Young adolescents' digital technology use and mental health symptoms: little evidence of longitudinal or daily linkages. Clin Psychol Sci 2019, 7:1416-1433.

55. Orben A, Dienlin T, Przybylski AK: Social media's enduring effect on adolescent life satisfaction. Proc Natl Acad Sci Unit States Am 2019, 116:10226-10228.

56. Przybylski AK, Nguyen T-vT, Law W, Weinstein N: Does taking a short break from social media have a positive effect on wellbeing? Evidence from three preregistered field experiments. J Technol Behav Sci 2021, 6:507-514.

57. Valkenburg PM, Peter J, Walther JB: Media effects: theory and research. Annu Rev Psychol 2016, 67:315-338.

58. Rideout V, Fox S: Digital health practices, social media use, and mental well-being among teens and young adults in the US. San Francisco, CA: HopeLab; 2018.

59. Bolger N, Zee K, Rossignac-Milon M, Hassin R: Causal processes in psychology are heterogeneous. J Exp Psychol Gen 2019 , 148:601-618.

This paper argues that people differ in their responses to environmental influences, but that most research has ignored this heterogeneity or has treated it as uninteresting error. The paper shows how causal effect heterogeneity can be modeled, and how it presents exciting opportunities for theory and methods.

60. Bryan CJ, Tipton E, Yeager DS: Behavioural science is unlikely to change the world without a heterogeneity revolution. Nat Human Behav 2021, 5:980-989.

Like Bolger et al. (see previous annotation), this study makes a strong case for why we need a causal effects heterogeneity paradigm in the social and behavioral sciences.

61. Valkenburg PM, Beyens I, Pouwels JL, van Driel II, Keijsers L: Social media and adolescents' self-esteem: heading for a person-specific media effects paradigm. J Commun 2021, 71 $56-78$.

62. Grice JW, Medellin E, Jones I, Horvath S, McDaniel H, O'lansen C, Baker M: Persons as effect sizes. Adv Method Prac Psychol Sci 2020, 3(4):443-455.

63. McNeish D, Hamaker EL: A primer on two-level dynamic structural equation models for intensive longitudinal data in Mplus. Psychol Methods 2020, 25:610-635.

64. Parry D, Fisher J, Mieczkowski H, Sewall C, Davidson BI: Social media and well-being: a methodological perspective. Curr Opin Psychol 2022, https://doi.org/10.1016/j.copsyc.2021.11.005.

65. Johannes N, Masur P, Vuorre M, Przybylski A: How should we investigate variation in the relation between social media and wellbeing?. 2021.

66. Valkenburg PM, Pouwels JL, Beyens I, van Driel II, Keijsers L: Adolescents' experiences on social media and their selfesteem: a person-specific susceptibility perspective. Technol Mind Behav 2021, 2(2).

67. Siebers T, Beyens I, Pouwels JL, Valkenburg PM: Social media are a powerful distractor for the vast majority of adolescents. 2021.

68. Rose $\mathrm{T}$ : The end of average: how to succeed in a world that values sameness. New York: Harper Collins; 2016. 